\title{
Médiévales
}

Langues, Textes, Histoire

61 | automne 2011

La chair des émotions

\section{Signes et couleurs des identités politiques du Moyen Âge à nos jours}

éd. Denise TURREL, Martin AURELl, Christine MANIGAND, Jérôme GRÉVY, Laurent HABLOT et Catalina GIRBEA, Rennes, Presses Universitaires de Rennes, 2008, 537 p. (Coll. Histoire)

\section{OpenEdition}

\section{Journals}

Édition électronique

URL : https://journals.openedition.org/medievales/6587

DOI : $10.4000 /$ medievales.6587

ISSN : 1777-5892

Éditeur

Presses universitaires de Vincennes

Édition imprimée

Date de publication : 20 décembre 2011

Pagination : 213-214

ISBN : $978-2-84292-337-2$

ISSN : 0751-2708

Référence électronique

«Signes et couleurs des identités politiques du Moyen Âge à nos jours », Médiévales [En ligne], $61 \mid$ automne 2011, mis en ligne le 21 janvier 2012, consulté le 22 avril 2022. URL : http://

journals.openedition.org/medievales/6587 ; DOI : https://doi.org/10.4000/medievales.6587

Ce document a été généré automatiquement le 22 avril 2022

Tous droits réservés 


\section{Signes et couleurs des identités politiques du Moyen Âge à nos jours}

éd. Denise TURREL, Martin AURELl, Christine MANIGAND, Jérôme GRÉVY, Laurent HABLOT et Catalina GIRBEA, Rennes, Presses Universitaires de Rennes, 2008, 537 p. (Coll. Histoire)

Ce volume, issu d'un colloque international tenu à Poitiers en 2007, replace dans l'histoire savante des questions qui en étaient jusque-là écartées. L'interdisciplinarité, et notamment l'approche anthropologique, a contribué à montrer l'intérêt de l'emblématique et de l'héraldique, alors que notre société en ignore largement les codes. Le choix de faire porter l'étude jusqu'au temps présent permet de montrer les évolutions ainsi que les permanences dans la longue durée des couleurs, des signes et des systèmes sémantiques. Il s'agit aussi pour les historiens de proposer une étude permettant de reprendre la main sur ce domaine, afin de ne pas laisser les interprétations ésotériques ou ésotérisantes avoir le haut du pavé.

2 Avant-propos, p. 7 - Michel Pastoureau, «Introduction. Pour une histoire des emblèmes et des couleurs ", p. 9-19.

3 I. Formes. Philippe Contamine, "Vive la croix gente, blanche et hautaine, Du beau jardin des nobles fleurs de lis. La croix droite blanche de France au $\mathrm{xv}^{\mathrm{e}}$ et au début du XvI siècle ", p. 23-44 - Betrand Schnerb, «La Croix de Saint-André, ensaigne congnoissable des Bourguignons», p. 45-55 - Laurent Hablot, «La croix noire des Bretons: un signe d'identité politique à travers l'histoire », p. 54-70 - Traian Sandu, «Signes et couleurs de la mobilisation fasciste dans un pays majoritairement agraire: le Mouvement légionnaire roumain", p. 71-88 - Jérôme Grévy, «Les trois couleurs nationales en France et en Italie », p. 89-114 - Guillaume Bourgeois, «L'héraldique de la faucille et du marteau dans l'univers communiste », p. 115-151.

4 II. Espaces. Werner Paravicini, "Signes et couleurs au concile de Constance: le témoignage d'un héraut d'armes portugais», p. 155-187 - Christine Lebeau, "Les images d'une monarchie composite: le jeu des couleurs entre la Maison d'Autriche et les "Pays héréditaires" ", p. 189-205 - Milena Lenderová, "Signes du patriotisme et vêtement féminin: une petite nation cherche son identité", p. 207-218 - Christian 
Joschke, «L'image comme pacte : Hambourg, 1893 », p. 219-232 - Anne Dulphy, « Signes et couleurs des Espagnols d'Algérie (1936-1945): identité nationale et politique», p. 233-248 - Stéphanie Michonneau, "Les couleurs de la nation en Catalogne», p. 249-271.

5 III. Fonctions. Édouard Bouyé, «Les clefs de saint Pierre, sur la terre comme au ciel », p. 275-311 - Simona Slanicka, «La fonction distinctive des ordres et du portrait noble dans les sociétés de cour ( $\mathrm{XIV}^{\mathrm{e}}-\mathrm{XVII}{ }^{\mathrm{e}}$ siècle) », p. 313-332 - Matteo Casini, «Les brigades de jeunes en Italie et leurs signes vestimentaires ( $\mathrm{XIV}^{\mathrm{e}}-\mathrm{XVI}^{\mathrm{e}}$ siècle) », p. 333-344 - Naïma Ghermani, "Le blason dans le portrait: d'une pratique dynastique à une pratique confessionnelle. L'exemple des portraits princiers dans l'empire au $\mathrm{xvI}^{\mathrm{e}}$ siècle", p. 345-364 - Catalina Girbea, « Flatteries héraldiques, propagande politique et armoiries symboliques dans quelques romans arthuriens (XII ${ }^{\mathrm{e}} \mathrm{XIII}{ }^{\mathrm{e}}$ siècle)", p. 365-380 - Hervé Drévillon, «La tenue militaire entre uniformité et distinction sous les règnes de Louis XIV et de Louis XV», p. 381-392 - Maciej Serwański, "Le costume "sarmate", trait distinctif de la noblesse polonaise aux XVI ${ }^{\mathrm{e}}$-XVII ${ }^{\mathrm{e}}$ siècles ", p. 393-408 - Luc Chantre, "Le drapeau vert du "Sultan rouge". Esquisse d'une symbolique des couleurs sous le régime hamidien ", p. 409-418.

6 IV. Pratiques. Laurent Vissière, "Dialogue des devises et devises en dialogue à l'occasion des premières Guerres d'Italie», p. 421-435 - Denise Turrel, «L'invention d'un signe politique: le panache blanc d'Henri IV», p. 437-458 - Fabrice Vigier, «Un enjeu politique? Les enseignes des auberges et des hôtelleries françaises en 1793-1794 », p. 459-476 - María Narbona Cárceles, « Le roi de la bonne foy. Charles III le Noble et les devises des Navarre-Évreux au Xve siècle », p. 477-509 - Elisabeth Elgán, « Les couleurs des féministes", p. 511-522 - Martin Aurell, Christine Manigand, " Conclusions », p. 523-530.

7 Contributeurs, p. 531-534 - Table des matières, p. 535-537. 